\title{
Diabetes Mellitus in the Services - A Review 1978-88
}

\author{
Lt Col G E Ratcliffe \\ MB, MRCP, RAMC \\ Consultant Physician \\ RAM College, Millbank, London SWI
}

SUMMARY: The incidence of diabetes mellitus in the Services for 1978-88 is reviewed. Its influence on the Serviceman' career in the long and short term is discussed. Mortality and morbidity rates are low in the Services when compared wit the general population, primarily because of the service demographic distribution. Problems with the discovery o asymptomatic diabetes and possible recommendations are discussed.

\section{Introduction}

Diabetes mellitus of whatever type automatically precludes service entry and will not be discussed further(1).

It is similarly easy to understand that the requirement of regular insulin injections in newly diagnosed young diabetics will preclude a full career for the serviceman of whatever trade. Severe permanent restrictions on him usually block promotion with consequent financial loss, and such restrictions are frequently considered unacceptable by patient and medical adviser alike, with medical discharge proving the most appropriate option to enable the new diabetic to pursue a more appropriate career as a civilian.

In older age groups approaching completion of service it may be more advantageous to servicemen and Service alike to allow him to continue his service in a reduced category, assuming satisfactory employment options are available. For example, employment on the training staff of a depot is a possibility.

The exact incidence of diabetis mellitus in the United Kingdom is not known, although the latest British Diabetic Association (BDA) figures state that there are 750,000 known diabetics, of whom 250,000 are insulin dependent. The BDA estimates a further 250,000 have undiagnosed diabetes (personal communication).

The main cause for concern lies in the non-insulin dependent group in whom there may be no symptoms for several years with the disease only coming to light when one of the known complications supervenes. Servicemen are required to attend for PULHHEEMS examinations throughout their careers and these become more frequent with time. As a result most such cases should be picked up relatively soon after onset, and certainly before the development of complications. Diabetic complications are rare amongst servicemen: this contrasts markedly with the high morbidity rates, bed occupancy rates and mortality rates in the civilian population. There were 22,920 admissions to NHS hospitals for diabetes in 1978 for men of age 15-44(2); 2228 beds daily were used by NHS patients for treatment of diabetes, compared with 15,829 for treatment of stroke; and there were 19 deaths per million males between the ages of 15 and 44 due to diabetes mellitus, and 184 deaths per million males of age group 45-56, 1985(3).

It is to be hoped that such complications, particularly vascular problems, can be prevented in the future? following recent advances in diabetic education, $\vec{\omega}$ development of human insulins, home monitoring! equipment and methods of insulin delivery in the lasf decade or so. One constant priority is the continuaer motivation of the patient.

\section{Incidence in the Services}

The population at risk in the Services remains faing constant with the demographic distribution in the thr Services being very similar up to the age of 45 , aboge which the Royal Air Force has a significantly higher proportion (Fig 1).

The MOD Stats computer at Stanmore produced complete lists of all new Service diabetics for the ye⿳r.s of the survey plus details of hospital admissions, details of medical discharges, lengths of hospital admission anc numbers of Service deaths in which diabetes might have been implicated. Each case was reviewed on the MOD Stats microfilm and all necessary information noted: in particular details of type of diabetes, details of family history of diabetes when available, and full clinicat details when diabetes as a possible cause of death were collected. In relation to the Royal Air Force, details o

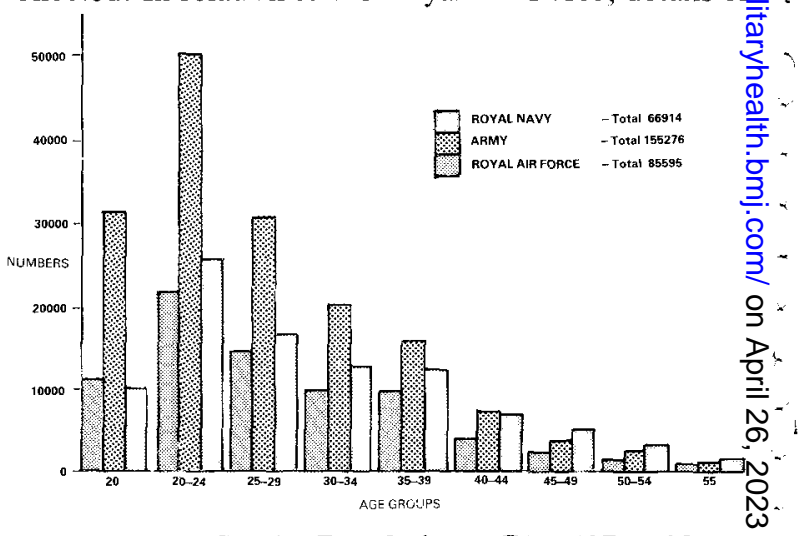

Fig 1. Mean Service Population at Risk 1979-1987 
method of presentation were also carefully noted to assist in predicting the incidence of undiagnosed diabetics in the Services as a whole.

It is important to emphasise that details of which type of diabetes are only available from 1983 onwards. It is also appreciated that some service cases of non-insulin dependent diabetes may have been treated only as outpatients, in which case they will have been omitted from the figures as MOD Stats only holds details of in-patients (Fig 2).

Details of family history of diabetics were only available in the original discharge summaries of $52 \%$ of the 1983-88 cases: this is a disappointingly low number when the stress put on accurate history taking is considered, particularly in a disease like diabetes mellitus.

Despite the frequency with which young servicemen with insulin dependent diabetes mellitus are discharged, diabetes mellitus remains low on the list of causes of medical discharge. Thus in 1987 seventeen diabetics were discharged in a total of 1048 discharged (4).

Fourteen servicemen(5) died in the period of this review in whom diabetes mellitus was considered partly the cause or an incidental association. Two died in accidents, one commited suicide, five died of myocardial infarction, one died following a stroke. One diabetic Gurkha died on leave in Nepal of cause unknown. Of the four deaths considered to be directly due to diabetes, there was some doubt in two. Therefore diabetes remains very low on the list of causes of service death.

Because most young servicemen who develop insulin independent diabetes leave the Service relatively soon after diagnosis, the long term complications are rarely seen. Bed occupancy rates to treat diabetic servicemen are infinitesimal compared with NHS figures, so that there were only 1719 service in-patient days in service hospitals in 1985(6). Beds in Service hospitals are occupied for the most part for initial stabilisation of diabetics and educational purposes and for blood sugar profiles for convenience rather than necessity, and not to treat complications.

\section{Diagnosis of Diabetes - Are Cases Missed?}

The exact incidence of diabetes mellitus in the UK is unknown with possibly as many as $25-30 \%$ remaining undiagnosed. A recent report from the Oxford region suggests the incidence in the under 21 age group is higher than original estimates(7). Routine examination of large numbers of the civilian population is time consuming and for various reasons, often financial, few such surveys have been performed. Assuming the British Diabetic Association figures are correct, then about $2 \%$ of the populus is diabetic. The majority of insulin dependent diabetics present with classical symptoms, viz polydypsia, polyuria and weight loss and the diagnosis is usually obvious. Non-insulin dependent diabetes is frequently picked up at routine examination: many cases remain asymptomatic.

\begin{tabular}{|c|c|c|c|c|}
\hline & & $\begin{array}{l}\text { Royal } \\
\text { Navy }\end{array}$ & Army & $\begin{array}{c}\text { Royal Air } \\
\text { Force }\end{array}$ \\
\hline \multicolumn{5}{|l|}{ Total Numbers, 1978-88 } \\
\hline Officers & & 20 & 78 & 45 \\
\hline RM Officers & & 2 & & \\
\hline Women Officers & & & 2 & 1 \\
\hline Gurkha Officers & & & 3 & \\
\hline Ratings/Soldiers/Ranks & & 157 & 400 & 257 \\
\hline Marines & & 17 & & \\
\hline Women Other Ranks & & 3 & 10 & 9 \\
\hline Gurkhas & & & 10 & \\
\hline \multicolumn{5}{|c|}{ Full Breakdown, 1983-88 } \\
\hline Officers & $\begin{array}{l}\text { NIDD } \\
\text { IDD }\end{array}$ & $\begin{array}{l}7 \\
5\end{array}$ & $\begin{array}{l}18 \\
12\end{array}$ & $\begin{array}{r}19 \\
6\end{array}$ \\
\hline RM Officers & IDD & 2 & & \\
\hline Women Officers & $\begin{array}{l}\text { NIDD } \\
\text { IDD }\end{array}$ & & 1 & 1 \\
\hline Gurkha Officers & NIDD & & 2 & \\
\hline Ratings/Soldiers/Ranks & $\begin{array}{l}\text { NIDD } \\
\text { IDD }\end{array}$ & $\begin{array}{l}30^{*} \\
53 \dagger\end{array}$ & $\begin{array}{r}51^{*} \\
133 \ddagger\end{array}$ & $\begin{array}{l}63 \\
67\end{array}$ \\
\hline Marines & IDD & 4 & & \\
\hline Women Other Ranks & $\begin{array}{r}\text { NIDD } \\
\text { IDD }\end{array}$ & 2 & $\begin{array}{l}1 \\
2\end{array}$ & \\
\hline Gurkhas & $\begin{array}{l}\text { NIDD } \\
\text { IDD }\end{array}$ & & 2 & \\
\hline Medical Discharges, 1978 & $8-88$ & & & \\
\hline Officers & & 7 & 10 & 8 \\
\hline RM Officers & & 1 & & \\
\hline Ratings/Soldiers/Ranks & & 77 & 159 & 22 \\
\hline Marines & & 6 & & \\
\hline Women Other Ranks & & 1 & 2 & \\
\hline Gurkhas & & & 2 & \\
\hline
\end{tabular}

Fig 2. Service Statistics, Diabetes Mellitus, 1978-88

IDD - Insulin dependent diabetes

NIDD - Non insulin dependent diabetes

*Includes 1 maturity onset diabetes of youth

$\dagger$ Includes 2 cases associated with chronic pancreatitis

$\ddagger$ Includes 1 case following pancreatectomy

One major survey to detect undiagnosed cases was conducted in Bedford in 1962(8). The protocol was to test urine samples from the 38,400 over the age of 21 on the electoral roll, obviously excluding the previously known diabetics. In fact 25,701 provided urine samples of which $1046(4 \%)$ were positive for glucose by Clinistix testing (Ames). Glucose tolerance tests, using 50G glucose loads, were performed in 911 of these patients. Demographic distribution of those considered to be diabetic by the criteria used at that time is demonstrated in Fig 3. Clearly the older the patient the more frequently does glycosuria indicate diabetes: at the same time renal threshold for glucose increases with age(9). Thus post-prandial glycosuria does not per se indicate diabetes: conversely a single post-prandial urine sample negative for glucose does not exclude it.

Despite the inherent difficulties with routine urine testing for glycosuria (of which the Bedford survey 


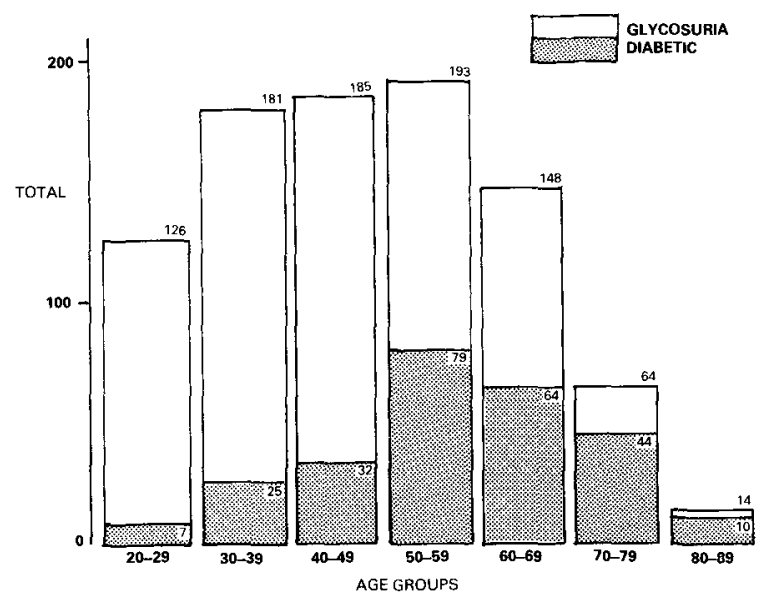

Fig 3. Bedford Survey 1962 - Diabetic Incidence/ Glycosuria Incidence

authors were fully aware - their original report criticised their own method and exposed its limitations(8)), the yardstick of glycosuria as a possible indicator of diabetes persists. Routine urine testing is part of the PULHHEEMS examination and, using the Bedford data applied to the demographic distribution of the Services, we can expect $0.88 \%$ of servicemen to have diabetes overall. Over the age of 40 this figure rises to almost $1 \%$. More significantly, of the new cases of diabetes diagnosed in the RAF during the years 1983$88,36.5 \%$ were picked up at routine examinations, preoperative assessments etc. Thus 58 new diabetics of a total of 159 were picked up randomly, of whom six were insulin independent.

The criteria for the diagnosis of diabetes mellitus(10) suggested by the World Health Organisation and the American Diabetes Association, are either a fasting venous or capillary whole blood glucose value equal to or greater than $7 \mathrm{mmol} / \mathrm{L}$ or a fasting venous plasm level of $8 \mathrm{mmol} / \mathrm{L}$. Any such result should be furthe asssessed by a $75 \mathrm{G}$ oral glucose load to confirm diabete 8 unless the diagnosis is obvious. These days when simple

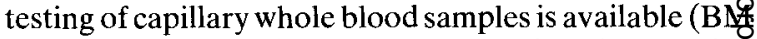
Stix, Dextrostix etc), it is recommended that routine fasting blood glucose estimations should be performe as part of the PULHHEEMS examination in servicemen of 40 or over rather than random urine testing to ensure that all new cases are detected, with confirmatory 75G glucose tolerance tests in dubious cases.

\section{Acknowledgements:}

I am very grateful for the advice and assistance of Margaret Sims of MOD Stats, Stanmore, to Mr Andiz Mackay for the graphics, and to Mrs Jean Hayman foco typing the manuscript.

\section{REFERENCES}

1. Pulhheems - a Joint Service System of Medical Classification 1976 JSP, Para 0435.

2. NHS Medical Health Statistics, England and Wales! HMSO 1979.

3. NHS Medical Health Statistics, England and Wales

4. Annual Health Tables, Royal Navy, Army, Royal tir Force 1987.

5. MOD Stats Tables (for years concerned).

6. MOD Stats Tables 1985.

7. BINGLEY P J, GALE E A M. Incidence of insulin depend diabetes in England: A Study in the Oxford region, 198 Br Med J 1989; 298: 558-60.

8. Sharp C L, Butterfield W J H, KeEn H. Diabetes Surefe. in Bedford 1962. Proc R Soc Med 1964; 57: 193-202.

9. Butterfield W J H, Keen H, Wickelow M J. Rega glucose threshold variations with age. $\mathrm{Br}$ Med $J 1967$, $505-7$.

10. Alberti K G M M, Hockaday T D R. Diabetes Mellitu只 In: Weatherall D J, Ledingham J G G, Warrell D A, edo् Oxford Textbook of Medicine 1st Edition Oxford Medic Publications: 1983: 9.5 . 